\title{
Filmens tekniker som litterär metod att gestalta våld och kroppslighet som känns mot huden: En medialitetsanalys av Mo Yans roman Ximen Nao och hans sju liv
}

\author{
Anneliese Fältström
}

[M]y body is not only an object among all objects, ... but an object which is sensitive to all the rest, which reverberates to all sounds, vibrates to all colours, and provides words with their primordial significance through the way in which it receives them 1

Att läsa Mo Yans roman Ximen Nao och hans sju liv (2016) är som att balansera med kroppen mellan vajande sorghumsfält, doften av blod och krut till ljuden av legender om reinkarnationens hemligheter. Läsningen är samtidigt en process för att kunna distansera sig från det våld och förtryck som gestaltas genom kroppen som förmedlande subjekt. Det innebär att läsaren är delaktig i realiseringen av textens gestaltning av våld och kroppslighet genom att det skapas en illusion av kroppslig identifikation. Wolfgang Iser beskriver denna dialog mellan text och läsare som en fenomenologisk process: "litterära texter omvandlar läsandet till en kreativ process som ligger högt över själva varseblivningen av det som står skrivet. Den litterära texten aktiverar våra egna själsförmögenheter och gör det möjligt för oss att återskapa den värld som denna presenterar" (1993: 324). Realiseringen av den värld som Mo Yan presenterar sker med andra ord i ett samspel mellan text och läsare genom att denne får möjlighet att reflektera över och kan leva sig in i en mikrohistoria traderad genom en gestaltning av utsatta kroppar. Man kan beskriva det som att romanens gestaltning av våld och kroppslighet överskrider litterära tekniker att gestalta som kan jämföras med filmens tekniker att skapa en illusion av kroppslig beröring. Dessa illustrationer av döda och lemlästade kroppar gestaltade genom filmens tekniker har således en säregen förmåga att kommunicera med läsaren. Vivian Sobchack förklarar denna översättningsprocess av att se våld och kroppslighet på film: "the film experience is meaningsful not to the side of our bodies but because of our bodies" (2004: 60).

I motsats till filmen som medium har en litterär text inte förmåga att bokstavligen visa färg och bild, eller producera ljud. Men texten har en förmåga att gestalta $\mathrm{i}$ analogi med audiovisuella mediers tekniker. Det är en litterär strategi som kan skapa en illusion av kroppslig identifikation genom en upplevelse av integrering av bild, rörelse och ljud i texten. Det erinrar om filmens tekniker att skapa kroppslig respons hos åskådaren kommunicerad genom en gestaltning av kroppslighet. Jämför med hur Claude Lévi-Strauss beskriver det: "Thought and sensibility take on a new dimension, in which every drop of sweat, every movement of muscle, every quickdrawn breath becomes the symbol of a story; and as my

1 I "What my Fingers Knew" (2004:53) citerar Vivian Sobchack Maurice Merleau-Ponty ur Phenomenology of Perception (2012). Citat kursivt i original. 
body reproduces the particular gait of that story, so does my mind embrace its meaning" (Sobchack 2004: 7). En gestaltning av kroppslighet som exempelvis bärare av historiska processer gör det intressant att fördjupa sig i Mo Yans författarskap genom en enskild roman. Min hypotes är att gestaltningen av det grymma våld och förtryck som kropparna utsätts för och som i vissa fall är fysiskt smärtsamt att läsa, fyller en funktion som en litterär metod att förmedla en historia som läsaren kan identifiera sig med genom hur det känns (jfr. De Groot, 2015: 214).

Avsikten med artikeln är att fördjupa mig i Mo Yans författarskap genom en medialitetsanalys av de inter- och intramediala strategierna i Ximen Nao och hans sju liv. Genom att fördjupa mig i några av de scener i romanen som innehåller kroppslighet och våld är ambitionen att identifiera de litterära strategier som i analogi med filmens tekniker manipulerar en kroppslig respons hos läsaren. Det är en form av medierad gestaltning som historiskt sett har tillskrivits filmens tekniker att genom narrativa grepp skapa kroppsmedvetande. Fokus i analysen är hur filmens tekniker som litterär metod kan upplevas lika skoningslöst (att läsa!) som filmens gestaltning. Det är ett omvänt perspektiv på text och bild som urskiljer sig genom gestaltningen av våld och där kroppens fysionomi och dess möte med våld är central. Utgångspunkten är att filmens förmåga att manipulera kroppslig respons bygger på kognitiva fenomen. Man kan uttrycka det som att de råa gestaltningarna av våld får mening genom hur de kommunicerar med läsaren genom: "('what it felt like') rather than textually" (De Groot, 2015: 214). För att beskriva de litterära strategier i Mo Yans roman som erinrar om filmens tekniker att gestalta våld och kroppslighet hämtar jag inspiration hos Vivian Sobchack. I "What my fingers knew. The cinesthetic subject, or vision in the flesh" undersöker hon på vilka sätt en gestaltning av kroppslighet och våld i film är troper som kan skapa en upplevelse av kroppslig identifikation. Hon lyfter även det faktum att forskningen om filmens kapacitet att skapa en illusion av kroppslig beröring har hamnat i skuggan av en forskning som fokuserar på filmmediets materialitet (2004: 59). En annan inspiration för att beskriva hur det är möjligt för en litterär text att skapa en illusion av kroppslig respons hos läsaren är Sarah J. Paulson. I "The body expressed in word and image: an attempt at defining Cora Sandel's aesthetics" ger hon exempel på estetiska tekniker att gestalta kroppslighet som överskrider textens/bildens gränser för att uttrycka processer utanför verkets materialitet (2007: 393).

Jag vill förtydliga att det inte är fråga om en assimilering av filmens tekniker då det rör sig om två medier som bygger på olika modalitet och med skilda mediakaraktäristiska uttryck. En assimilering indikerar en sammansmältning av verbalt och visuellt medium (vilket inte är fallet!) eftersom mediet inte ska betraktas som monomedialt. Snarare skapas det genom litterära strategier en illusion av att texten har iscensatt gestaltningen genom att imitera filmens berättartekniker. Det som är relevant är alltså inte att identifiera på vilka sätt medierna skiljer sig från varandra, utan vad litterär text har gemensamt med exempelvis film och bild. Se exempelvis Beate Schirrmacher som med stöd i Lars Elleströms teorier om medium och modalitet, beskriver intermedialitet som: "ett överbryggande av mediala skillnader med hjälp av transmediala gemensamheter" (2013: 32). Det är en syn på medier som i ett samspel öppnar för ett intersektionellt perspektiv på läsningen av romanen. I texten är det snarare ett intermedialt samspel mellan verbal och visuell representation som urskiljer sig, än en rangordning mellan text och bild/film. Det gör det möjligt att knyta begreppet 
intersektionalitet till de maktordningar som Mo Yan belyser, samtidigt som det illustrerar den historiskt sett hierarkiska synen om att bild/film som medier är underordnade litterär text.

\section{Mo Yan och Ximen Nao och hans sju liv}

Mo Yan2 (f. 1950) betraktas som en av den kinesiska samtidslitteraturens främste författare. Hans romaner har översatts till 18 språk varav sju av dem till svenska. Fyra av romanerna, däribland Ximen Nao och hans sju liv, har översatts från kinesiska av sinologen och översättaren Anna Gustafsson Chen. Det faktum att texten läses i översättning innebär att läsaren behöver ta ställning till att romanen endast utgör en representation av den ursprungliga texten. På så sätt är texten avskild sin ursprungskontext, men samtidigt i ett samspel mellan kulturella och språkliga diskurser. Se exempelvis Chen Maiping: "There is a context for the original text, and there is also a context for its translation into another language; this is called 'co-contextualization.' Contemporary comparative literature is based on just such a complicated network of texts" (2015: 34). Precis som Mo Yans roman är en mediering mellan språkliga och kulturella diskurser, pendlar den litterära texten mellan olika mediers tekniker att gestalta. Det ger en extra dimension till romanen och vilka historiska processer den kommunicerar utanför själva texten.

År 2012 tilldelades Mo Yan Nobelpriset i litteratur. Det gav upphov till kritik från akademiker och författarkollegor som ansåg att han förhöll sig passiv till kommunistregimen. Hans författarskap betraktades snarare som ett uttryck för Mao Zedongs vision om ett socialistiskt samhälle. Denna vision var ett av kulturrevolutionens mål och det utmynnade i utrensning av oliktänkande genom etnisk förföljelse och folkmord. Bortsett från kritiken mot Mo Yan för att han inte aktivt tar avstånd från regimen, är de närgångna gestaltningarna av våld någonting som kritiseras. Hans romaner förmedlas ofta i recensioner som en excess $\mathrm{i}$ våld och lemlästade kroppar. Det är problematiskt att kritiken inte tar hänsyn till att, när det gäller litteratur från länder i Asien som exempelvis Kina, det finns ett perspektiv på politisk makt knuten till rätten till yttrandefrihet och censur. Romanerna måste läsas på sociokulturella villkor med en förståelse för den samhällskritik som döljer sig bakom metaforer och språkliga ironier. Se exempelvis Chengzhou He (2014: 87).

Den som är bekant med Mo Yans författarskap känner sannolikt igen den idiosynkrasi som urskiljer sig i texten genom en illusion av motsägelsefullhet mellan textens gestaltning och vilka associationer den väcker. Det kan vara ord som skapar omvända associationer hos läsaren som exempelvis doften istället för lukten av blod, eller en spänning mellan det poetiska språket som gestaltar det kaotiska och intima våldet. Ximen Nao och hans sju liv innehåller även en polyfon röst. Den ger uttryck för individuella och kollektiva erfarenheter av politiskt förtryck. Polyfonin urskiljer sig framförallt genom ett metareflektivt perspektiv på berättarröster inom romanens fiktion. Det skapar ett intryck av att texten består av flera stämmor som överlappar varandra och det understryker samspelet mellan text, musik och film i romanen. Bland annat lyfts polyfonin fram genom att Mo Yan uppträder som en slags mise-en-abyme gestalt som en av romanens fiktiva karaktär, berättarröst eller fiktiva text. Jämför med hur romanens fiktiva karaktär Ximen Gris berättar: "det vore dumt att fästa

2 Namnet Mo Yan som är en pseudonym för Guan Moye betyder tala inte 
någon större tilltro till det han [Mo Yan] skriver, eftersom hans berättelser alltid är insvepta i dimmor och består av vilda funderingar som bör granskas ordentligt" (2016: 340). Det metareflektiva perspektivet på berättarröster har en illusionsbrytande funktion som utmanar fiktionens gränser. Men det belyser även det intermediala samspelet mellan visuellt och verbalt språk i texten. De i vissa fall motsägelsefulla rösterna inom romanen är på sätt och vis en instruktion till läsaren att reflektera över fiktion och realism och den historia som förmedlas.

I Ximen Nao och hans sju liv utgår Mo Yan från, som i de flesta av sina romaner, hembyn Gaomi där han växte upp som son till en lantbrukare. Berättelsen är knuten till denna plats, men speglar samtidigt ett mikroperspektiv på Kina och kan på så sätt betraktas som ett utsnitt av Kinas politiska historia. Läsaren får följa karaktärerna från början av 1950-talet då Kulturrevolutionen låg i sin linda och jordreformer och kollektivisering var ett faktum, genom revolutionen och Maos förtryck och de politiska effekterna efter hans död fram till millennieskiftet 2000. Berättelsen är en ond men hisnande vacker saga och en labyrint av drömmar och röster ur det förflutna, men den prövar även gränsen mellan organiskt och oorganiskt liv. Romanen inleds med att Ximen Nao som är berättelsens huvudsaklige berättarröst avrättas av revolutionära bönder. Innan han förlorar sin människogestalt presenteras han för kung Yama som ställer honom inför ett ultimatum. Om han inte erkänner en skuld som är knuten till att han äger sin egen mark, döms han att reinkarneras som åsna. Ximen vägrar att erkänna skuld. Han torteras och lämnas med kroppen tömd på vätska och sönderbrända muskler i en pöl av kokande olja för att tänka över sina oförrätter. Under de kommande femtio åren möter Ximen Nao olika existentiella prövningar, kärlekens plågor och ond bråd död och han vet inte hur han ska kunna undkomma återfödelsens cykler. Han reinkarneras som åsna, tjur, gris, och hund för att efter en tid i apans gestalt, återfödas som det nya millenniets förstfödde människobarn. Ur olika perspektiv på Ximen Naos blick får läsaren följa med på en resa genom ett utsnitt av Kinas historia. Men även möjlighet att identifiera sig med den kinesiska befolkningens lidanden och kamp för överlevnad och drömmen om kulturell identitet.

\section{Tidigare forskning och teoretiskt ramverk}

I analysen är avsikten att introducera en alternativ läsning av Mo Yans roman genom ett fokus på samspelet mellan medier knutet till en gestaltning av våld och kroppslighet och vad dessa troper kommunicerar för mening utanför texten. Att fokusera på våld och kroppslighet är intressant då det bortsett från Mo Yans eventuella politiska agenda är våldet $\mathrm{i}$ hans romaner som framförallt kritiseras i recensioner. Att betrakta romanen som en medierad fiktion genom att bland annat identifiera de intramediala fenomenen, skapar ett utvidgat perspektiv på den forskning som finns om Mo Yans författarskap som inriktar sig på intertextualitet. Se exempelvis Chen Maiping: "The Intertextual Reading of Chinese Literature: With Mo Yan's Works as Examples" (2015). Ett intertextuellt perspektiv på läsningen av Mo Yans roman kan överbrygga kulturella och språkliga diskurser genom att det uppmärksammar och tar hänsyn till relationen till andra texter inom och mellan olika diskurser. Man kan beskriva det som att det belyser dialogen mellan kulturella och språkliga diskurser. Exempelvis genom att uppmärksamma referenser i romanen till Gabriel Garcia 
Marquez magiska realism, eller till Lev Tolstoj, vars roman Anna Karenina Mo Yan refererar till i Ximen Nao och hans sju liv (2016: 445). Det placerar Mo Yans författarskap i en tradition av en världslitteratur vars syfte är att översättas för att på så sätt cirkulera utanför sin urspungskontext, enligt Chen: "some Chinese writers do not write for Chinese readers, but for readers in other languages. This is known as writing for the translation. The text is therefore disconnected from the Chinese context and associations" (2015: 35).

Jag menar att ett intermedialt perspektiv på Mo Yans roman kompletterar forskningen om intertextualitet, samtidigt som det utgör ett utvidgat perspektiv. I texten urskiljer sig förutom de intermediala fenomen som uppmärksammar dialogen mellan medier, intramediala fenomen som pekar tillbaka mot den litterära texten, exempelvis genom referenser till andra texter. På samma sätt som en intertextuell läsning fokuserar på dialogen mellan historiska texter och kulturella diskurser och vad som händer med texten när den rör sig mellan språkliga och kulturella system, definierar intramedialitet fenomen i texten som exempelvis pekar tillbaka mot skrivandet som en metod att vittna om det förflutna. De intramediala fenomenen urskiljer sig bland annat genom referenser till historiska texter ur världslitteraturen, fiktiva och autentiska, till opera och teater, eller genom en fiktiv Mo Yan inom romanens fiktion. På så sätt finns det en samsyn mellan intermedialitet och intertextualitet som öppnar för läsningar som inte inordnar texten i enskilda diskurser, eller rangordnar dem i en hierarkisk ordning. Båda begreppen innebär en inkluderande läsning av Mo Yans roman(er) som en litteratur som ingår i en global litteraturmarknad. Enligt Chen: "[it] places Mo Yan in the context of international literary tradition, and offers an intertextual reading between Mo Yan and other traditional texts in world literature" (2015: 35).

Gestaltningen av våld och kroppslighet i kinesisk litteratur och vad dessa troper speglar för processer utanför texten är teman som varit och är föremål för forskningens intresse. Bland annat genom Michael Berry: "A history of pain: trauma in modern Chinese literature and film" (2008). Berry undersöker våld gestaltat i kinesisk film och litteratur som ett uttryck för ett kollektivt minne om politiskt förtryck. Forskningen om Mo Yans roman(er) som särskilt lyfter visuella element i texten som kan knytas till våld och kroppslighet som ett uttryck för historiska processer framstår som begränsad. I "Mo Yan's Life and death are wearing me out in a cultural and visual context" har Yuhan Huang ett intermedialt perspektiv på Ximen Nao och hans sju liv genom en studie av representationen av propagandaposters. Fokus är mediekombinationer som affischer, reklambilder och illustrationer och de tolkas som ett uttryck för de politiska spänningar som följde på kulturrevolutionen (Huang 2014: 107). I "There is no end to violence" lyfter Shelley W. Chan våldet i Mo Yans romaner som ett uttryck för en subversiv röst om politiskt förtryck. Den subversiva rösten är möjlig att knyta till ett intermedialt perspektiv genom att den uppmärksammar litterära strategier i texten som måste läsas bortom dess semantiska betydelse. Chan uppmärksamma även hur Mo Yan använder litterära strategier för att genom dessa skapa en illusion av ljud, bild, färg, doft och rörelse på ett sätt som erinrar om filmens tekniker (2011: 164).

I analysen refererar jag övergripande till Lars Elleströms teorier om medium och modalitet som han ger uttryck för i "The Modalities of Media: A Model for Understanding Intermedial Relations.” Enligt Elleström är det omöjligt att greppa vad intermedialitet är utan att förstå de grundläggande aspekterna av vad som karaktäriserar ett medium (2010: 11). Det gör det nödvändigt att ge en kortfattad introduktion till vad som är ett medium bortom, som 
Elleström beskriver dess basala betydelse: "a channel for the mediation of information and entertainment" (2010: 17). För att urskilja hur mediefenomen kan kombineras, transformeras och/eller integreras, det vill säga vilka fyra byggstenar som konstituerar ett medium snarare än vad det är per definition, har Elleström utvecklat en modalitetsmodell som bygger på ett fundament av tre ben: "basic media, qualified media and technical media" (2010: 12). Basmediet är texten (inom romanen) och definieras utifrån dess modalitet. Det kvalificerade mediet är exempelvis romanen eller filmen som är beroende av att kontextualiseras för meningsproduktionen. Det tekniska mediet är pärmen/fodralet som omger texterna och realiserar mediet. Bas- och kvalificerat medium är med andra ord innehåll medan ett tekniskt medium är materialisering av innehåll. Utifrån dessa tre kategorier av mediets teoretiska form definierar Elleström ett mediums modalitet som kan appliceras över texten som ett raster för att urskilja på vilka sätt mediala fenomen realiseras och hur realiseringen kommer till uttryck. Beate Schirrmacher redogör för dem och dess funktion på ett pedagogiskt sätt med utgångspunkt i Elleströms schema varför jag använder mig av hennes definition. Förenklat består ett medium av fyra modaliteter: "vilket tekniskt medium som används (bok, dator, kropp, ljudvågor), vilka sinnen som tilltalas (auditiva, visuella, taktila), vilket semiotiskt system som används eller skapas (ikoniskt, indexikaliskt, symboliskt) och hur ett medium förhåller sig till tid och rum" (2013: 32). Det är dock viktigt att betona att, enligt Schirrmacher, alla medier har dessa modaliteter gemensamt och att "det är grunden av gemensamma egenskaper som möjliggör intermedial växelverkan” (2013: 32).

Begreppet intermedialitet kan beskrivas som närvaron av skilda mediefenomen inom ett mediums konventionella gränser, hur de samverkar inom mediet och i dialog med andra medier. Enligt Jørgen Bruhn: "[H]ur ett till synes homogent medium inom mediets egna gränser har en eller flera förbindelser med andra medier" (2008: 24). Begreppet intramedialitet kan beskrivas som närvaron av självreflektiva fenomen inom ett medium. I artikeln avses med begreppet de fenomen som pekar tillbaka mot den litterära texten genom direkta och indirekta referenser till litterära genrer, litterära verk och/ eller författare (fiktiva och historiska) och till läsande och skrivande som en process. De intramediala referenserna kontrasterar mot de intermediala som urskiljer sig inom mediet men refererar till andra medier än litteratur. Som exempelvis film och bildkonst. De intramediala referenserna definierar med andra ord för den litterära texten mediekaraktäristiska fenomen. I analysen använder jag begreppen inter- och intramedial referens, formell imitation och medial projicering. Inter- och intramedialitet definierar de mediefenomen som urskiljer sig inom det egna mediet som en slags intertext (intramedialitet), eller en litterär text som refererar till en annan medietext som exempelvis film (intermedialitet). Formell imitation definierar en mer genomgripande förändring av mediets konstitution. Exempelvis en text som imiterar vad som betraktas som filmens mediekaraktäristiska berättartekniker. Medial projicering definierar de intermediala fenomen i en text som gestaltar genom ett annat mediums tekniker. Exempelvis genom att romanens karaktär upplever verkligheten som om den vore en film eller en tavla. Begreppen är Bruhns definition ur The intermediality of narrative literature: Medialities matter (2016: 27ff). I den introducerar Bruhn en trestegsmodell som en metod att analysera narrativa texter med fokus på representationen av mediefenomen. Bruhn beskriver modellen som: "a method of analyzing narrative written literature that is at the same time sufficiently 
open towards improvisation and creativity to be useful when analyzing the individual complexities of specific narrative texts" (2016:30).

Avsikten är inte att redovisa de tre stegen i artikeln. Men kännedom om modellen kan skapa förståelse för den komplexa läsprocess som föregår analysen och att den har sin utgångspunkt $\mathrm{i}$ ett tvärvetenskapligt perspektiv. Se exempelvis Bruhn som beskriver överbryggandet av mediateori och textanalytisk metod: "there is an unproductive distance between the rich theoritization in media studies and intermedial studies on the one hand, and specific, hands-on analytical practice on the other. It is this gap my model specifically aims to overcome" (2016: 34). I min forskning har jag inspirerats av Bruhns modell för att i första hand fokusera de inter- och intramediala strategierna i texten och identifiera de som till synes har en självreflektiv funktion. Men även för att identifiera de som skapar en illusion av texten som filmisk och på vilka sätt det realiseras i texten i analogi med filmens tekniker. Fokus under inläsningen var de medieringar i romanen som ingav illusionen av kroppslig identifikation. Analysmetoden utgör ett alternativ till intertextuell analys som är en essentiell del av forskningen om Mo Yans författarskap. Ett tvärvetenskapligt perspektiv kan dock skapa en fördjupad förståelse för Mo Yans författarskap och att blandningen av medierepresentationer är en litterär metod att vittna om den kinesiska befolkningens existentiella villkor både under och efter kulturrevolutionen.

\section{Analys}

Analysen är strukturerad i tre avsnitt som övergripande speglar romanens inledande kapitels inter- och intramediala strategier genom tre av Ximen Naos reinkarnationer: "Åsnans prövningar", "Tjurens styrka" och "Grisens glädje." Fokus är de intermediala strategier som associerar till filmens tekniker och hur de urskiljer sig genom en gestaltning av kroppslighet och våld. Men även hur texten genom att imitera filmens tekniker skapar kroppsmedvetande och en illusion av upplevd närvaro i gestaltningen. De intramediala strategier som pekar tillbaka mot texten som medium urskiljer sig huvudsakligen genom ett metareflektivt perspektiv på berättarröster. De intramediala strategierna förstärker de intermediala och meningsproduktionen är till synes beroende av detta samspel. Eftersom gestaltningen av våld, om man läser texten bokstavligt, riktar sig mot djurkroppar finns det en risk att det skapas distans till gestaltningarna och att romanen betraktas som en fabel. Därför ber jag läsaren att se människan Ximen under huden på åsnan, tjuren och grisen och att läsa de kroppsliga gestaltningarna som en antropomorf för de människor som inte tillåts en röst.

\section{Ximen Nao målas med åsneblod och byter skepnad}

I "Åsnans prövningar" gestaltas Ximen Nao som i ett ontologiskt vakuum mellan organiskt och oorganiskt liv och som en hybrid gestalt mellan olika livsformer. Avrättad, torterad och avskild sin kroppshud, ledsagas han genom en välvd underjordisk tunnel. Tunneln han färdas genom är upplyst av skenet från "lykthållarna" och "vampyrfladdermössens" lysande ögon. Lyktskenet reflekterar de "gigantiska spindlar" som hänger ner från "tunnelns välvda tak" (2016: 24). Tunneln utgör således en medial projicering som indikerar ett begränsat synfält. Intrycket förstärks genom visuella markörer i analogi med seendeprocessen som "lyktsken", 
"gula pupiller", eller "gyllene stjärnor" (2016: 24). Detta fokus på ett begränsat synfält har samma funktion som gestaltningen genom filmkamerans lins och det associerar till upplevelsen av att se film. De projiceringar som associerar till att se film utmärker sig genom att Ximen Nao reflekterar över de bilder av ansikten som passerar revy när hans kropp transporteras genom dödsrikets tunnlar: "De var precis som människor. Det enda som utmärkte dem var att deras hud tycktes vara färgad med någon underlig vätska och gav ifrån sig bländande blå gnistor [...] och glänsande ögon som skimrar i mörkret” (2016: 24). Människornas hud som tycks färgad och bländande blå erinrar om det artificiella skenet från Tv-skärmen eller bioduken och är en medial projicering, med Bruhns definition av begreppet, en litterär gestaltning genom filmens tekniker: "which may include a much wider array of medial phenomena. Perceiving and describing particular aspects of the world as if it was, or could have been, either a qualified mediality (like 'music' or more specific 'a symphony'), or a technical mediality (a TV screen, a canvas)" (2016: 28). Till skillnad mot en ikonisk projicering som gestaltar en inramning av bilden som en tavla, markerar tunneln med sitt välvda tak och referenser till filmkamerans lins, ett tidsligt förlopp. Det skapar en illusion av rörelse i texten $\mathrm{i}$ analogi med filmens förmåga att projicera en gestaltning.

I "Åsnans prövningar" urskiljer sig en mångfald medierepresentationer som rör sig inom och mellan medier. Referenserna till medier "vädjar till läsaren att tolka texten som om det rörde som en text transformerad till film" (Ohlsson 1998: 207). De framträder genom komplexa perspektivbyten knutna till vem som berättar, ur vilken position eller genom fiktiva texter som skapar en motsägelsefull bild. Förskjutningarna av berättarperspektiv genom fiktiva texter i relief till berättarröst, har samma funktion som kamerans panorering av miljöer och/eller karaktärernas inre tankar. Berättarrösterna upplevs som simultana i texten. Det skapar en illusion av att dialogen består av flera stämmor. Rösterna ger sig ofta till känna inom samma stycke och gestaltas ur ett icke linjärt kronologiskt perspektiv på tid och rum. Det skapar en spänning mellan vem det är som talar, men också en spänning mellan bild, text och kontext. Denna spänning i texten urskiljer sig i den scen som föregår Ximen Naos reinkarnation som åsna. Inledningsvis befinner sig Ximen i dödsriket "Svedd och tömd på vätska" ligger han i "pölen av olja" och hör "knastrandet från [sina] sönderbrända muskler" (2016: 21). Genom en metaleps som indikerar en förskjutning av berättarnivåer färdas han över "Gaomi nordöstra härad." Han reflekterar över "varje berg, varje vattendrag, varje gräsplätt, varje träd" och han betraktar sin söndertrasade kropp utspilld över "de vita vintermelonstora stenarna" under brospannet (2016: 24ff).

Läsarens blick fastnar i den inramning som brospannet skapar, men illusionen av rörlig bild förstärks genom att Ximen Nao, nu genom en proleps, betraktar sig själv och världen ur det begränsade perspektivet av en dörrspringa: "genom dörrspringan kunde [han] se människor skynda fram och tillbaka" (2016: 27). Det är genom den smala dörrspringan han ser tillbaka på sig själv på stenbron med en gevärsmynning riktad mot pannan. Han beskriver eldskenet från geväret, hur han "hörde" en smäll som verkade komma långt bortifrån och kände doften av krut i luften (2016: 27). Han betraktar den sargade kropp som en gång var hans utspilld under bron: "Strax fick jag syn på stenskravlet nedanför brofästet, som bytt färg efter att det dränkts i mitt kött och blod" (2016: 26). Den smygande blicken på världen genom den smala dörrspringan erinrar om en voyeuristisk blick som kan knytas till fascinationen av att se en gestaltning av kroppslighet och våld på film. Det är ett perspektiv 
som jag återkommer till i analysen "Grisens glädje." Dessa litterära strategier i texten är en formell imitation av filmens teknik att gestalta händelser till synes synkront genom en manipulation av bildrutor som fungerar som en länk mellan tid och rum. Bruhn beskriver begreppet "formal imitation" som en litterär strategi och en metod att överbrygga en gestaltnings skilda tids- och rumsskikt: 'It may 'shut down' a scene, bring it to a halt and possibly to a closure, or it may work as a gateway between different aspects of reality-for instance from reality to dream, or from present to past" (2016: 53). Det skiftande berättarperspektivet erinrar om hur film kan använda litterära tekniker för sin gestaltning som exempelvis "voice-over" (Abbott 2008: 79). Denna voice-overeffekt fungerar för filmen som en "framing advice", enligt Abbott en påminnelse om: "that the sound of the voice must share the sensory arena with the visual" (2008: 79). På samma sätt kan en kursivering av texten fungera som en instruktion till läsaren om en förskjutning av berättarperspektiv och utgör på så sätt en litterär "framing advice.” Ett exempel är Ximen Åsnas (驢) första stapplande steg som föl, men rösten som är applicerad över gestaltningen är Ximen Naos: "Mina barn! Far saknar er! Far hoppades att ni skulle växa upp till riktiga drakar och fenixfåglar som skänkte släkten ära, men istället blev ni en annans barn och er far förvandlades till åsna!" (2016: 37)

De medierepresentationer som illusoriskt refererar till verbalt och visuellt språk och som upplevs synkrona i texten, lyfts fram genom en gestaltning av kroppslighet och kroppens reaktion på trauma. Det erinrar om filmens språklighet och förmåga att gestalta kroppslighet som fysiskt berör åskådaren. Men det utgör även en parallell till textens kapacitet att skapa likvärdiga affekter hos läsaren. Det avgörande är inte mediets materialitet utan en kombination av: "the choise of technique" (Paulson 2007: 393) och läsarens kognitiva förmåga att: "återskapa den värld som [texten] presenterar" (Iser 1993: 324). Paulson beskriver skillnaden i upplevelsen av kroppslighet beroende på medium som att åskådaren av bild/film måste förhålla sig till bilden, medan en text erbjuder läsaren att intellektuellt skapa en vision (Paulson 2007: 393). Åskådaren av bild/film blir delaktig i realiseringen genom svårigheten att värja sig. Det är, enligt Anne Gjelsvik, en sådan gestaltning som berör genom att den riktar sig direkt mot blicken: "violence against the eye, against perception, something that is forced upon you and that you can't protect yourself from or transform into something else like metaphor, so that you can distance yourself from it" (2013: 256).

Ximen Naos reinkarnation som åsna är ett exempel på en litterär gestaltning som erinrar om det audiovisuella mediets förmåga att genom kameratekniker som närbilder involvera åskådaren i gestaltningen. Ximen Naos transformation filtreras genom hans kroppsliga situation med ett narrativt fokus på hans upplösta kropp och kroppsvätskor som blod. Den kroppsliga förvandlingen är ett exempel på en verbal gestaltning genom visuell representation. Jämför med Paulson som beskriver det som en: “'embodied gaze' or personal 'style' and artistic representation of the body" (2007: 388). Ximen Nao gestaltas som i en parallell verklighet mellan olika livsformer. Fången i dödsriket beskriver han de bilder av: "snön som låg kvar i skuggiga diken och bäckar som återkastade det skarpa dagsljuset" som passerar revy för hans inre. I slutet av tunneln möts han av två blå demoner med en "blodfläckad spann" (2016: 23ff). I citatet nedan har jag kursiverat ett urval av intermediala referenser som associerar till filmens tekniker att gestalta tid och konstens förmåga att fånga 
ögonblicket, men även de medieringar som i likhet med film och konst väcker kroppsmedvetande:

En vedervärdig doft stack mig i näsan, kväljande och varm som en levande åsna. Bilden av ett slaktat djur fladdrade förbi min hjärna och försvann. Demonen med träplattan grep tag i en pensel av svinborst och smetade ut ett lager klibbigt, mörkrött blod över mitt huvud. En underlig blandning av smärta, domning och stygn från tusen vassa nålar fick mig att vråla. Från huden hördes ett svagt fräsande och jag kände hur blodet trängde in i det brända köttet på samma sätt som när den uttorkade jorden plötsligt välsignas med ett sött regn. Demonen drog drag efter drag med penseln, som en skicklig och snabb lackerare, tills åsneblodet täckte hela mig (2016: 23).

I citatet urskiljer sig bland andra medierepresentationer som erinrar om filmens audiovisuella gestaltning. De ger sig tillkänna genom auditiva och visuella markörer som betraktade tillsammans informerar läsaren om att tolka texten som en filmisk gestaltning. Det urskiljer sig genom ord som direkt och indirekt vädjar till läsarens "bildseende" (Ohlsson 2002:239), exempelvis genom hur Ximen Nao betraktar hur "[b]ilden av ett slaktat djur fladdrade förbi [hans] hjärna och försvann" (2016: 23). Eller genom projiceringar som får läsaren att associera till filmens akustiska förmåga genom ord som "hördes", "fräsande" och "vråla" (2016: 23). I texten är det även möjligt att identifiera ett perspektiv på rumslighet genom referenser till bildkonstens förmåga att gestalta ögonblicket. Det urskiljer sig genom ord som "pensel", "träplattan" och den mörkröda färgen som tränger in i målarduken på samma sätt som åsneblodet tränger in i Ximen Naos "brända kött" (2016: 23). Instruktioner i texten om kroppens reaktion på smärta, domning och "blodet som trängde in i det brända köttet... som... plötsligt välsignas med ett sött regn" har samma funktion i texten som närbilder av utsatta kroppar har för filmen. Jämför med hur Paulson beskriver förhållandet mellan Sandels/Fabricius texter/målningar: "Here bodily movements function in the same way as colors, lines and shapes do in Sara Fabricius paintings" (2007: 388). De intermediala referenserna i texten som belyser textens förmåga att iscensätta en gestaltning genom filmens tekniker urskiljer sig i narrationen snarare än genom intramediala referenser till verkliga eller fiktiva medierepresentationer. På så sätt är de en formell imitation av filmens tekniker. Det bör noteras att film/ konst inte nämns direkt i texten, men Ximen Naos transformation till åsna gestaltas genom sådana strategier som enligt Bruhn: "makes use of devices strongly related to cinematic form in general, and more specifically to the dissolve process used in film" (2016: 52).

I vissa avsnitt är de intra- och intermediala referenserna till synes så sammansvetsade att de är omöjliga att särskilja utan att meningsproduktionen går förlorad. De överlappar varandra och urskiljer sig genom referenser till bild och litterär text. Som i gestaltningen av Ximen Naos transformation mellan dödsriket och hans första reinkarnation. Gestaltningen innehåller intermediala referenser som erinrar om filmens tekniker och pekar mot filmmediet som källa och dess estetiska funktion. Men den innehåller även referenser till litteratur och textens mediekarakteristiska förmåga att gestalta. Ximen Nao beskriver hur de demoner som ledsagar honom genom de underjordiska tunnlarna "liknade sminkade skådespelare" som en referens till teatern och filmens värld, men han tillägger att man "i denna värld aldrig skulle hitta en så underbar och ren blå färg” (2016: 25). Det är en subtil referens till romanens värld och textens förmåga att imitera men inte visa färg och bild. De intramediala strategierna 
urskiljer sig framförallt genom ett metareflektivt perspektiv som pekar tillbaka mot den litterära texten som medium vilket problematiserar rätten till en röst. Rösten och rätten att tala är återkommande genom metareflektiva instruktioner i texten om att Mo Yan borde "hålla tyst", eller att han "hittar på" (2016: 34). Rösten lyfts fram i texten genom kommentarer om hur en litterär text är berättartekniskt konstruerad vilket belyser textens förmåga till medieöverskridande gestaltning.

Det är ett perspektiv som särskilt framträder genom textens dialog mellan Jiefang och hans barnbarn. Dialogen är konstruerad genom komplexa analepser och prolepser som förstärker intrycket av att rösterna överlappar varandra. Inledningsvis talar Lan Qiansui (barnbarnet). Han riktar sig till ett fiktivt du i romanen: "Vet du vem Lan Jiefang är?" I nästa mening skiftar perspektivet och det är Ximen Nao som talar utifrån ett tredjepersonsperspektiv: "frågar plötsligt vår berättare - Lan Qiansui, det lilla barnet med de gammalmansskarpa ögonen, den tunna kroppen och den överväldigande svadan." I den avslutande meningen sker ytterligare ett perspektivskifte och det är Jiefang som svarar sitt barnbarn: "Såklart jag vet. Det är ju jag! Lan Lian var min far och Yingchun min mor. Men om din historia stämmer måste du ha varit en av våra åsnor?” (2016:38). Dialogen är en instruktion till läsaren om textens komplexa berättarnivåer, men dialogen bekräftar även karaktärernas inbördes kroppsliga och emotionella relationer och det flytande perspektivet på tid och rum. Det får betydelse för meningsproduktionen. Se exempelvis Chi-ying: "times, similar scenarios in different parts of the novel narrated from different perspectives intensify the inner coherence, multiply the layers of meaning, and make a fuller account of the episodes" (2014: 126). Dessa olika röster som till synes är simultana är en metareflektiv litterär strategi som skapar en illusion av polyfoni i texten. Man kan uttrycka det som att perspektivet på berättarnivåer har en illusionsbrytande funktion. Härigenom ifrågasätts och understryks gränsen mellan litterär gestaltning och filmens tekniker. Det är ett perspektiv som förstärks genom hur Mo Yans röst till synes sträcker sig utanför texten för att gestalta historiska processer. Det lilla barnet med en gammal mans ögon och överväldigande svada framstår som en karikatyr av Mo Yan själv. I romanen som helhet är han återkommande representerad i egenskap av författaren som skriker ut sitt budskap i "megafon" (2016: 139), som en skrävlare och "rackare på att ljuga" (2016: 34).

\section{En blodig tragedi under månen}

Ximen Åsna går en grym död till mötes. Ihjälslagen av svältande bönder bevittnar han "[a]llt som hänt under de tio år som gått" sedan han reinkarnerades första gången. Hans minnen "blixtrade förbi för [hans] inre syn." Han ser klubban träffa honom i huvudet och själen "lämna[de] kroppen och sväva[de] upp i himlen [...]. På avstånd [ser] han hur männen stycka[r] den döda åsnekroppen i ett antal mindre bitar” (2016: 124).

I "Tjurens styrka" urskiljer sig ett komplext samspel mellan medierepresentationer knutna till minnen som ett sätt att gestalta. Enligt Bruhn: "literature [can] uses sound, music, painting, and cinematic devices to produce and reproduce fictive memories" (2016: 58). Samspelet mellan medier understryker att de minnen som återberättas muntligt, skriftligt eller genom bildfragment och som erinrar om konst och/eller filmens tekniker, är en metod att vittna om och bearbeta det förflutna. Gestaltningarna hämtar bland annat inspiration ur den 
kinesiska muntliga traditionen där kroppslighet och kroppens förgänglighet är central. Texten är i likhet med avsnittet om Ximen Åsna konstruerad genom en mångfald av berättarperspektiv och röster som överskrider det realistiska. Men texten överskrider även vad som historiskt sett definierar språklighet genom upplevelsen av att text och bild är integrerade. Den hybrida gestaltningen av minnen, vem i texten som talar, för vems räkning och vems minnen det är som återberättas, ger intryck av en polyfoni som överskrider texten som medium. Det framhäver de auditiva elementen. På så sätt inger textens gestaltning en illusion av att den är konstruerad av muntligt och skriftligt språk. Jämför med Anders Olsson som beskriver det polyfona perspektivet som en dragkamp mellan ett centripetalt och centrifugalt språk (2011: 58).

Man kan beskriva det som att det i texten pågår en strid mellan olika språkliga diskurser. Texten är "modersmålet" och illusionen av film/bild inom texten en medierepresentation som "bidrar till att skapa den skenbara men illusoriska enheten hos modersmålet" (Olsson 2011: 58). Det ger intryck av en mångstämmighet som förstärks genom att Mo Yan själv uppträder som en fiktiv karaktär i romanen eller genom fiktiva essäer och noveller för att inom mediets konventionella gränser ställas till svars för hur han återger det förflutna. Hans roll beskrivs exempelvis av karaktären Ximen Nao: "Hela novellen är en lång dröm, ett minne som Mo Yan fabricerade en kväll många år senare när han var i fyllan och villan [...] Det Mo Yan skrev är till nittionio procent lögn" (2016: 347). Författaren i texten har en performativ funktion som erinrar om filmens cameo. Med andra ord en motsvarighet till regissörens gästspel inom filmens fiktion. Det är en litterär strategi som enligt Chengzhou skapar "multiple effects, which is illustrative of what was referred to earlier as performanz. They suggest that the author's experience of a slip between fiction and reality and his enjoyment of the freedom are narrated in the imaginary world of his creation" (2014: 85).

Till skillnad från "Åsnans prövningar" som är berättad ur Ximen Åsnas perspektiv, är "Tjurens styrka" berättad ur Ximens framtida farfar Jiefangs ej linjära perspektiv på tid och rum. Samspelet mellan inter- och intramediala referenser ger sig tillkänna i texten genom tidshopp som analepser och prolepser knutna till att minnas och återberätta, skriftligt och muntligt. Jiefang berättar: "Det är sant att jag är en man på drygt femtio och du är en femårig pojke, men om vi går tillbaka fyrtio år i tiden, till den turbulenta våren 1965, så var jag en femtonårig yngling och du en ung tjur" (2016: 137). I texten berättar Jiefang för sitt barnbarn hur Ximen efter att han har reinkarnerats som tjur säljs till hans far. Fadern fastnar för tjurens ögon som påminner honom om hans egen far (Ximen Nao).

Dessa minnen projicerade genom tjurens blick, blixtrar förbi som "en scen ur en utländsk film" och får Jiefang att flera år senare, när han återberättar historien för sitt barnbarn, minnas hur hans far såg på tjuren som en som "återser en älskad som han länge varit skild från" (2016: 132). Texten innehåller direkta referenser till film i synergi med ord som "ögon" och "återspeglade" (2016: 132). Orden markerar en medial projicering som bekräftar gestaltningen som: "“framed' not as if the surroundings are reality, but as if they were a picture, in 'iconic projections." (Bruhn 2016: 47). Det är farfaderns röst men tjurens minnen som återges: "Jag berättar det ur ett människoperspektiv, men du såg det med en tjurs ögon. Kanske vore din berättelse mer intressant. Inte det? Nå, då fortsätter jag väl” (2016: 195ff). Men det är likväl barnbarnets röst och tjurens minnen som återskapas i texten: "Jag har berättat för dig om mitt liv som åsna och du vet det mesta av det som hände sedan. Under de 
år jag levde som tjur följde jag dig i hälarna som en skugga och du känner till nästan allt jag var med om" (2016:129). Dessa gestaltningar knutna till minne och förflutenhet förmedlade genom text och referenser till muntlig tradition, är ett intermedialt perspektiv som bygger på kognitiva processer: "the "process of remembering is a process of visualization, activated and realized either as film or a photograph." (Bruhn, 2016: 55).3 De intramediala referenserna är invävda $\mathrm{i}$ texten. De identifierar skrivandet och återberättandet som en minnesprocess att förmedla det förflutna och de löper till synes parallella genom referenser till bild och konst. Det är genom att minnas, vittna och återberätta som samspelet mellan medier i texten är som mest framträdande. Det understryker den muntliga traditionens kraft att gestalta det förflutna, både muntligt men även skriftligt som ett sätt att vittna om förtryck. Som Jiefang beskriver det: "Allt det där hände och det som har hänt är historia och att återberätta historien för de som var där men har glömt detaljerna, det är min plikt" (2016: 240). Temat att minnas och återberätta visualiseras huvudsakligen genom en gestaltning av kroppslighet som någonting fragmentariskt och som en palimpsest av kroppar och kroppsminnen ur det förflutna. Ett exempel är hur Jiefang överskrider ett perspektiv på tid och rum när han ger sig tillkänna i förfluten tid såväl som i framtid. Inledningsvis talar han ur det förflutna, en 15-årig pojke som ser Ximen Tjur (牛) och inte sitt barnbarn framför sig: ”§̊ Ximen Tjur jag orkar knappt berätta om vilket våld han utsatte dig för" (2016: 240).

I meningen efter har det skett en multiperspektivisk förskjutning med samma litterära funktion som filmens teknik att manipulera bildrutor för att skildra karaktärer, tid och rum ur ett icke kronologiskt perspektiv. Här är det Jiefang som återberättar för sitt barnbarn: "Sedan du var tjur har du reinkarnerats fyra gånger och färdats fram och tillbaka genom dödsriket, så det är möjligt att du redan har glömt detaljerna, men jag kommer aldrig att glömma det jag såg” (2016: 240). Textens gestaltning av binära tids- och rumsskikt är en formell imitation av filmens tekniker med samma funktion som filmens övergång mellan två scener. Samtidigt som det $\mathrm{i}$ texten finns intermediala referenser till filmens formspråk, urskiljer sig intramediala referenser som pekar tillbaka mot texten. Det bekräftar romanens gestaltning som ett sätt att vittna om förtryck. Som Huang beskriver det: "He [Jiefang] expresses the responsibility to retell what he has witnessed, just as it is the responsibility of all individuals to do" (2014: 116). Jiefang berättar för sitt barnbarn att han "är tvungen att tala" och att vittna om Ximen Tjurs grymma öde. Hans minnen utgör en visualisering av dagen som ett "grönskande träd" och han kan se "vartenda litet löv" framför sig (2016: 241). Orden framhäver dessa visualiserade minnen och vädjar till läsaren att översätta texten till en bild i tid. Som filmens gestaltning av ett förlopp, eller en bild i rum, som fotografiets/bildens gestaltning av ögonblicket. Jiefang berättar att han kan se sig själv som femtonårig pojke bevittna hur Ximen Tjur misshandlas av upproriska bönder då han vägrar att acceptera jordreformerna. Han beskriver gruppen av män som höjer sina piskor och piskslagen som lämnar djupa blödande skärsår i Ximen Tjurs hud. Han hör "det dova ljudet" (2016: 241) när slagen träffar kroppen, som en auditiv gestaltning av ljuden som ekar i luften och vinandet av piskorna som får luften att dallra. Han ser på sitt barnbarn, men han ser också sin far och inser att denne känner varje slag som träffar tjuren och han minns "[d]e heta tårarna som rann ur [tjurens] slutna ögon som fick pälsen på [hans] huvud att mörkna” (2016: 241). Jiefang beskriver för

3 Bruhn citerar Wyllie, B. 2003. Nabokov at the movies: Film perspectives in fiction. Jefferson:McFarland \& Co 
sitt barnbarn hur männen dansar runt tjuren som nu ligger "med mulen nedtryckt i leran" (2016: 243) men hur de fortsätter slå och sparka på den livlösa kroppen.

På så sätt erinrar textens gestaltning av Jiefang och hans barnbarn om bildens montagetekniker. Dialogen utspelar sig till synes samtidigt, men i skilda tidsskikt. Jiefang förmedlar rädslan i blicken på Ximen Tjurs mor som stel av skräck bevittnar misshandeln och han återger hur bönderna fjättrar henne med ett rep vid Ximens nosring för att tvinga honom att resa sig: "Men du reste dig inte, och jag visste att du aldrig skulle göra det - för i så fall hade du inte varit Ximen Tjur längre" (2016: 244). Han berättar hur nosringen brister av dragkampen och hur det får den mjuka mulen att slitas sönder: "Ett ljud som från ett nyfött, gråtande spädbarn sipprade ut ur dina näsborrar och fick mitt hjärta att brista. Å, Ximen Tjur! Och så rämnade nosen med ett högt, skärande ljud och huvudet föll till marken med en duns" (2016: 244). Dessa gestaltningar som rör sig mellan olika nivåer av berättarperspektiv och kroppslighet har, som jag redogjort för inledningsvis i min analys, en multiperspektivisk funktion som indikerar en förskjutning av berättarperspektiv. Denna förskjutning kan som i analysen av Ximen Åsna gestaltas litterärt genom en kursivering av text. Men den kan även gestaltas, som i dialogen mellan Jiefang och hans barnbarn, genom auditiva element i texten. Ljudet från piskorna, nosringen som brister och rämnar "med ett högt skärande ljud som gråten från ett spädbarn", är en litterär strategi som har en liknande funktion för texten som filmens teknik att identifiera en karaktär eller skiftet av berättare, genom ett musikaliskt tema som följer karaktären. De auditiva elementen förstärker textens gestaltning av faderns och Jiefangs kroppsliga respons av misshandeln. Det belyser samspelet mellan auditiva och visuella uttryck inom texten. Liksom en iscensättning av bild i kombination med musik i film förstärker en gestaltning av kroppslighet och våld, har texten förmåga att genom litterära strategier gestalta genom en illusion av musikalisk iscensättning. Enligt Sobchack: "Even at the movies our vision and hearing are informed and given meaning by our other modes of sensory access to the world: our capacity not only to see and to hear but also to touch, to smell, to taste, and always to proprioceptively feel our weight, dimension, gravity, and movement in the world" (2004: 60).

De litterära strategier i texten som associerar till filmens förmåga att skapa kroppsmedvetande urskiljer sig framförallt genom referenser till ett åskådarperspektiv. Det skapar en upplevd närvaro i gestaltningen. Exempelvis genom skildringen av hur Jiefangs far och Ximen Tjurs mor bevittnar misshandeln. Textens brutala gestaltning skapar avsky men även en fascination som erinrar om den attraktion som är knuten till gestaltning av våld på film. Gestaltningen av kroppslighet och våld bär på en ambivalens som får blicken att fastna i våldet, men den inger även en känsla av avsky och lust att väja med blicken. Denna fascination förmedlas genom Jiefangs berättelse. Snyftande ber han männen sluta. Han beskriver den skara åskådare som omringar scenen "för att titta på spektaklet [...] De ville absolut se denna blodiga tragedi" (2016: 243) och han berättar hur "männen tog några steg tillbaka." De betraktar tjuren, men fortsätter låta piskorna vina och Jiefang berättar hur piskslagen "ritade ett rutmönster på [tjurens] rygg" som börjar blöda ymnigt "tills rygg och mage liknade stycken av blodigt kött på en skärbräda" (2016: 242ff). I texten har det rutmönster som bildas på tjurens rygg samma funktion för texten som filmens närbilder av utsatta kroppar. På så sätt är den en litterär gestaltning av filmens manipulerade bildsekvens. Inom texten finns subtila instruktioner till läsaren om att en gestaltning av våld mot kroppen 
har en särskild förmåga att manipulera åskådaren emotionellt. Det ger uttryck för en gestaltning som är särskilt svår att distansera sig från då den riktar sig mot blicken. Det urskiljer sig bland annat genom hur Jiefang berättar att hans far inte förmår se våldet och hur han gömmer ansiktet för att slippa se.

Det urskiljer sig även genom beskrivningen av faderns kroppsliga reaktioner. Jiefang berättar: "Jag såg hur far slängde plogen åt sidan, föll framstupa till marken och grävde ned händerna och ansiktet i jorden. Han darrade [...] och jag visste att han led lika mycket som tjuren" (2016:245). Jiefang ser männen falla i trans av slagen. De slutar slå tillfälligt när de blir tvungna att reflektera över våldets mening: "[de] drog sig plötsligt till minnes olika gamla moralregler och legender. Var det här djuret verkligen en tjur? Eller kanske ett slags gudomlighet, en Buddha som uthärdade allt för att rädda vilsegångna människor och leda dem till upplysning” (2016:243). Svårt misshandlad med det mörka blodet rinnande från den sönderslitna mulen reser Ximen Tjur slutligen på sig till åskådarnas beundrande utrop: "Att en tjur som inte hade en kroppsdel i behåll kunde resa sig och gå var ett mirakel" (2016:245). Scenen utspelar sig på över nio sidor. Avrättningen av Ximen Tjur är illustrativt gestaltad och bitvis svår att läsa, men ger uttryck för en gestaltning iscensatt genom filmens audiovisuella tekniker.

\section{En grym stridsscen som väcker åskådarnas intresse}

Efter ett tragiskt liv begravs Ximen Tjur på den plats där han föll omkull: "Ximen Tjur! - du som hellre dog än reste dig för att plöja folkkommunen" (2016: 244), nedgrävd på den bit mark som tillhör Jiefangs far, den sista fribonden i Kina. Tjurens minne bleknar och ersätts av Ximen Naos (2016: 251). Återigen reinkarnerad förbannar han den dag han föddes: "Släpp mig fri! Låt mig sträcka på mig och spräcka detta smutsiga, avskyvärda svinskal så att jag kan växa och återta Ximen Naos manliga gestalt igen!" (2016: 254).

I "Grisens glädje” är det liksom i övriga kapitel möjligt att identifiera en integrering av medierepresentationer knutna till att minnas. Det ger uttryck för gestaltningen som en metod att förmedla erfarenheter ur det förflutna. Dessa minnen illustreras genom Ximen Gris blick såväl som genom den röst som fiktiva texter och medieringar i texten består av. De ger sig tillkänna genom ett självreflektivt perspektiv på litterär text. Exempelvis genom hur Ximen Gris, då han inser att han snart kommer dö, erinrar sig den dagen som "en dag lika lång som hundra år" (2016:445) som en referens till Gabriel Garcia Marquez roman Hundra år av ensamhet (1967). Han minns känslan av att läsa Lev Tolstojs Anna Karenina (1873) och han kan kroppsligen identifiera sig med Anna Kareninas smärta som fick henne att kasta sig framför tåget. Liksom i "Åsnans prövningar" är de komplexa berättarnivåerna framträdande som en litterär strategi att introducera en ny berättare, eller som en upplysning om att det inom texten har skett en förskjutning av tid och rum. Exempelvis genom Ximen Naos kursiva utrop som jag beskrev i analysen av Ximen Åsna, är en litterär strategi med samma funktion för texten som "voice-over" för filmen. Om medieringarna i "Tjurens styrka" och "Åsnans prövningar" är förankrade i berättarnivåerna, är de i "Grisens glädje" en instruktion till läsaren om att åskådarperspektivet är knutet till berättarperspektivet. I avsnittet är de intramediala referenser som pekar tillbaka mot texten som medium särskilt framträdande genom gestaltningen av Ximen Gris minnen. Dessa minnen filtreras genom 
ögonvittnesskildringar och fiktiva texter som beskriver närgångna bilder av kroppslighet och våld, eller genom scener som präglas av passion.

Det är en voyeuristisk blick som urskiljer sig i texten och som gör läsaren delaktig i en gestaltning av kroppslighet, våld och sex. Den voyeuristiska blicken erinrar om den fascination som är knuten till en gestaltning av kroppslighet på film, men den har också en psykologisk effekt som skapar en illusion av närhet i gestaltningen. Den voyeuristiska blicken urskiljer sig ur ett metareflektivt perspektiv och den är knuten till vem som talar och vem som ser. Det är blickperspektivet som lyfts fram i textens gestaltning av en kärleksscen som Ximen Gris bevittnat i smyg och i skydd av trädens lövverk. Han reflekterar över hur "månen skymta[r] fram mellan grenarna - stor och rund, som om den skurits ur en tennplatta" och han ser hur den speglar sig i floden, så overklig men övertygande genom "det klara skenet" (2016: 324). Månens reflex i vattenytan får honom att minnas en kärleksscen som han läst ur Mo Yans fiktiva essä: "Strålande aprikosblommor" (2016: 324). Den skymtande månen markerar en visuell inramning i texten som erinrar om filmens gestaltning. Den erinrar även om kameralinsens voyeuristiska blick som gör åskådaren delaktig i gestaltningen av den scen som utspelar sig under månen. Illusionen av rörlig bild förstärks genom ord i texten som associerar till kameran lins och filmens förmåga att projicera. Som den stora runda månen som illustreras som skuren ur en tennplatta som erinrar om filmens förmåga att återge genom sken.

Den kärleksscen som utspelar sig i skuggan av ett blommande aprikosträd återges som en dialog mellan Ximen Gris minnesbild och Mo Yans fiktiva essä. Ximen Gris berättar att han minns hur kärleksparet "rörde sig så hetsigt att blombladen föll som snö över marken" och han läser Mo Yans version: "En lätt vindfläkt fick de översta grenarna att röra sig och tunna blomblad föll som snö och lade sig på marken i ett vackert, jadeliknande täcke" (2016: 324ff). Gestaltningen av fallande blomblad är en eufemism för den kärleksscen som Ximen Gris minns. Den är samtidigt Mo Yans litterära gestaltning ur den fiktiva essän. Textens presentation av kärleksscenen har samma funktion som filmens gestaltning av erotik och nakna kroppar som kan upplevas problematisk och därför förläggs utanför bild. I texten urskiljer sig med andra ord ett komplext samspel mellan verbalt och visuellt språk som kan knytas till litteraturens förmåga att gestalta minnen genom filmens tekniker. Det belyser litteraturens makt att vittna och återberätta och det belyser samspelet mellan intra- och intermediala referenser i den aktuella romanen. Den voyeuristiska blicken som associerar till ett åskådarperspektiv förmedlas även genom textens gestaltning av Tv-mediets närgångna rapportering och kamerans fokus på döda och lemlästade kroppar. De intermediala gestaltningarna är en litterär strategi med samma funktion som filmens närbilder. Representationen av medier inom textens konventionella gränser understryker hur de interoch intramediala referenserna löper till synes synkront. De intramediala fenomenen förstärker de intermediala och är ofta representerade som berättarröster och fiktiva texter inom samma stycke. Det gör det till synes omöjligt att separera dem utan att textens meningsbärande funktion går förlorad.

Betraktade som i ett samspel ger medieringarna intryck av en medvetenhet hos Mo Yan om författarens möjlighet att gestalta verkligheten som om den vore en film, som en metod att förmedla historiska processer men undgå censur. De medierade gestaltningarna urskiljer 
sig genom hur Ximen Gris (豬) minnen förmedlas i texten. Knutna till faktiska och fiktiva litterära verk och kontaminerade av ögonvittnesskildringar är gestaltningarna ett kluster av referenser till text, bild och opera. Samspelet mellan medier urskiljer sig även genom referenser till adaptionsprocessen och dess förmåga att kommunicera en gestaltning mellan medietexter. Detta perspektiv på transformation av text mellan medier visualiseras genom en instruktion $\mathrm{i}$ texten om att den massaker Ximen Gris återberättar bygger på en fiktiv "Maoqiangopera" som Mo Yan gör anspråk på. Operan är i sin tur en mediering av en fiktiv novell som Mo Yan "senare, i efterordet till sin novell [»Om svinuppfödning«] hävda[de] att han hade varit medförfattare till [...] men jag är säker på att det är mest struntprat" (2016: 381). Ximen Gris minnen förmedlas i relief till dessa fiktiva texter. På så sätt får läsaren olika perspektiv på massakern. Den version som Ximen Gris återger är i huvudsak Mo Yans ur hans fiktiva novell: "Om svinuppfödning." Ximen Gris läser ur novellen och han beskriver den emotionella effekt som läsningen har på honom: "Det var knappt jag stod ut med att läsa [de grymma stridsscenerna]":

Den 3 januari 1982 satte en grupp på tio personer under ledning av den före detta soldaten Zhao Yonggang, som deltagit i Vietnamkriget, och med den erfarne jägaren Qioa Feipeng som rådgivare, kurs mot sandön i motorbåtar [....] På fem sekunder avfyrade de sju gevären minst hundrafyrtio kulor som fällde de drygt trettio vildsvinskrigare. Alla hade träffats i huvudet. Kulorna trängde in genom rustningen och exploderade inne i skallen. Det var en grym död deras hjärnsubstans rann ut på marken och för vissa trängde ögonen ut ur sina hålor [...] Tre eldflammor - tre enorma brinnande drakar - flög ur eldkastarnas munstycken med ett dån som av hundratals tjattrande gäss. Elddrakarna ringlade sina klibbiga tungor runt Trasöra och förenades till en tre meter hög brasa (2016: 436ff)

Citatet är ett exempel på textens förmåga att överskrida den abstrakta gränsen mellan verbalt och visuellt språk. Till skillnad från en visuell gestaltning som realiseras genom att åskådaren, enligt Paulson "co construct the images," realiseras textens gestaltning genom att läsaren "co create a vision (2007: 393). Texten innehåller auditiva illustrationer som "dånet av hundratals tjattrande gäss", men även visuella referenser till blicken som erinrar om filmens förmåga att projicera en verklighet genom ord som "eldsflammor."

De intermediala fenomen som är framträdande är de som erinrar om filmens mediakaraktäristiska tekniker att skapa kroppslig identifikation med en gestaltning, enligt Sobchack: "[t]he film is [a]n unremittingly sensuous experience of music and fabric, of mud and flesh" (2004: 53). Denna illusion av kroppslighet knuten till upplevelsen av att se film är till synes konstruerad av litterära strategier $\mathrm{i}$ analogi med filmens tekniker att genom närbilder på lemlästade kroppar skapa en "immediate tactile shock when flesh first touches flesh in close up" (Sobchack 2004: 53). Som exempelvis elddrakarnas ringlande, klibbiga tungor som skapar en länk mellan textens gestaltning av kroppslighet och väcker läsarens identifikation. Textens gestaltning av kroppslighet får en meningsbärande funktion som en materialisering av det förflutna. Enligt Sobchack: "the lived body both provides and enacts a commutative reversibility between subjective feelings and objective knowledge, between the senses and their sense or conscious meaning" (2004: 61). Att det finns ett samspel mellan visuellt och verbalt språk urskiljer sig även ur ett åskådarperspektiv och omgivningens och mediabevakningens fascination för de massakrerade kropparna. Det är ur det perspektivet som Ximen Gris vittnar om sin erfarenhet av massakern och som han återger minnet av de 
överlevare som flyttar döda och lemlästade kroppar för att placera dem: "på någon öppen plats så att folk kunde få se de[m] på nära håll” (2016: 439). Samspelet urskiljer sig bland annat genom referenser till medias skriftliga och muntliga rapportering av döda kroppar i relief till Ximen Gris redogörelse: "Journalister från länets olika tidningar och radiostationer följde expeditionen i hälarna och lämnade täta och lätt extatiska rapporter. »Alla gator och gränder tömdes« och »åskådarleden var tjocka som murar«" (2016: 439). Vittnesmålet är kontaminerat av Mo Yans version ur hans fiktiva essä om konsekvenserna av massakern: "En enorm trupp på mer än ettusen svinkadaver låg och ruttnade i floden. De svällde, exploderade och blev mat åt maskar och fiskar på sin långsamma färd. Till sist försvann de i det vilda havets svallande vågor: åts upp, upplöstes, omvandlades till en massa olika substanser och blev en del av livets oändliga, aldrig avstannande kretslopp" (2016: 395).

Minnet av massakern och synen och stanken av ruttnande kroppar i kontrast till hur den återges i den fiktiva essän, får Ximen Gris att känna "fysisk avtrubbning, förvrängning och förstoring" (2016: 440ff). Textens fokus på kroppslig identifikation med de upplösta kadavren erinrar på så sätt om filmen som upplevelsecentrum och filmmediets kapacitet att skapa en illusion av en förvrängd och förstorad verklighet. Samtidigt reflekterar Ximen över det stora intresset för dessa döda, fragmentariska kroppar och han överväger att "börja ta betalt av åskådarna" för att få se dessa. Som han säger: "en yan för att få titta, två yan för att fotografera sig tillsammans med kadavret [...] fem yan för ett foto där man satt grensle över det döda svinets rygg och tio yan för en bild på både liket och medlemmarna i jaktlaget" (2016: 439). Ximen Gris upplevelse av fysisk avtrubbning och förvrängd verklighetsuppfattning kan knytas till ett åskådarperspektiv och filmens förmåga att etablera kroppslig respons. Se exempelvis Kristina Stenström som i beskriver hur dessa gestaltningar av "överskridna kroppsliga gränser" och "[k]roppens avbildning i skräcken" väcker en lust, men också ett kroppsmedvetande: "[e]n lust som till stora delar är förknippad med det fysiska svar som medieupplevelsen kan ge hos sin publik" (2015: 65).

\section{Avslutande diskussion}

Avsikten med artikeln var att analysera Mo Yans roman Ximen Nao och hans sju liv med fokus på samspelet mellan medier inom romanen. Men också att presentera Mo Yans litterära strategier som en metod att förmedla processer utanför texten. Att betrakta romanen som ett medierat vittnesmål om förtryck väcker frågor om autenticitet och rätten till en röst. Det väcker även frågor om vems historia det är som återges. Rösten och rätten att tala är ett genomgående tema i romanen. Det komplexa perspektivet på berättarröster som talar utifrån en till synes motsägelsefull agenda har en illusionsbrytande funktion som kommer till uttryck genom en upplevd polyfoni i texten. Det bekräftar att texten innehåller spår av visuellt och verbalt språk och det understryker dialogen mellan text och bild. Jag menar att Mo Yans röst inom fiktionen $\mathrm{i}$ form av fiktiva essäer och noveller är en litterär strategi med samma funktion som filmens "[c]inematic intimate writing" (Rossholm 2013: 217). Mo Yan manipulerar romanens fiktion och gör sig till en del av den. Det innebär att han kan gestalta en sociopolitisk historia ur till synes olika perspektiv.

Det är en utmaning att identifiera de litterära strategier som i analogi med filmens tekniker har en förmåga att väcka kroppslig identifikation hos läsaren. Särskilt eftersom det historiskt 
sett är forskningens dilemma att etablera en empirisk förklaring till audiovisuella mediers kapacitet att skapa kroppsmedvetande hos åskådaren annat än ur ett metaforiskt perspektiv, se Sobchack (2004: 58). Intermedialitet som berättarstrategi och språklig diskurs kan imitera filmens språk och ge röst till de färger, bilder och ljud som texten inte förmår visa. Enligt Gabriele Rippl: "The visual representation cannot represent itself; it must be represented by discourse" (2015: 130). Genom analysen av Ximen Naos skepnader urskiljer sig återkommande litterära strategier som till synes överskrider text och bild som ett uttryck för processer utanför texten. De inter- och intramediala strategierna ger sig tillkänna genom ett åskådarperspektiv knutet till att minnas och återberätta skriftligt och muntligt och genom en gestaltning av kroppens reaktioner på trauma som erinrar om filmens tekniker. De förmedlas även genom intramediala referenser till litteratur som ett sätt att minnas och vittna. Minnena gestaltas som ett våld mot individen och som ett strukturellt och epistemologiskt våld riktat mot befolkningen. Bruhn beskriver det som medieringar som: "inte bara representerar världen direkt, utan snarare orkestrerar en sammansmältning av mediala representationer i en komplex text, som består av flera olika medier, och där relationen mellan medierna utgörs av en strid som på ett mer eller mindre direkt sätt uttrycker konflikter utanför textens rum" (2008: 31).

Våld och kroppslighet är det nav som romanen spinner om och ett tema som kommunicerar den kinesiska befolkningens erfarenheter ur ett mikroperspektiv. Det kommer till uttryck genom en illusion av ett samspel mellan inter- och intramediala strategier i gestaltningen av ett åskådarperspektiv. Det lyfter fram en spänning utanför texten. Det ger intryck av, som jag lyfte fram i avsnittet om Ximen Gris, en medvetenhet hos Mo Yan om författarens möjlighet att gestalta en verklighet som om den vore en film för att förmedla historiska processer men undgå censur. Den litterära gestaltningen av journalistiska mediers rapportering av massakern genom närgångna bilder på lemlästade kroppar och omgivningens fascination av nyhetsrapporteringen erinrar om filmens dokufiktion. Det är en dimension till litterär gestaltning som Josette Féral beskriver som: "a slice of reality imported 'as is' into the theatrical framework, but the image is mediated (2011: 52). Referenser i texten till dokumentära inslag som tidnings- och Tv-mediets nyhetsrapportering, understryker en performativ gestaltning av kroppslighet och våld. Gestaltningarna skapar samma ambivalens som filmens eller Tv-mediets förmedling av en fiktiv ramberättelse genom autentiska bilder eller vittnesmål inom fiktionen. Enligt Féral: "[T] hese scenes bring art, particularly theatrical art, out of its theatrical framework to create the event, in truth, the spectacular, onstage by substituting a violent performativity accompanied by a sense of extreme presence identical to that experienced when faced with a real event" (2011: 52).

Dessa medieringar knutna till att minnas och återberätta belyser perspektivet på intermedialitet som forskningsdisciplin som en röst mellan textytor i dialog med samhälleliga strukturer utanför texten. Det är ett utvidgat perspektiv på litterär gestaltning som kan knytas till hur Mo Yans roman(er) generellt tolkas utifrån en västerländsk diskurs. Härigenom upplever jag en parallell till en av ambitionerna med intermedialitet som forskningsdisciplin. Närmare bestämt att pröva den abstrakta skärningspunkten mellan medier. Som teoretisk grund kan intermedialitet ifrågasätta den historiskt sett hierarkiska synen om konstarternas status. Det vill säga inställningen att bild/film har lägre status än litterär text. Det erinrar om hur litteratur från bland annat Kina marginaliseras i förhållande till västerländska litterära 
verk. Parallellen mellan postkolonial teoribildning och intermedialitet uppmärksammas även av Kamilla Elliott som beskriver det i relation till adaptionsprocessen: "As postcolonial scholars attend to how colonized subjects talk and write back to their colonizers (e.g. Spivak 1985: 120ff), so too, adaptations need to talk, write, film, dance, sculpt, game, compose, costume, photograph and computer program (etc.) back to the theories that have colonized them" (2013: 37). Ett intermedialt perspektiv på Mo Yans roman(er) kan således problematisera det faktum att litteratur från länder utanför väst ofta tolkas utifrån ett perspektiv på politik och etnicitet, eller filtreras genom västerländska genrer. Utgångspunkten är att det är samma mekanismer som styr de tankemönster som internaliserar det koloniserade subjektet under kolonisatörens blick och en hierarkisk syn på medietexternas status. Det är ett perspektiv jag har burit med mig i analysen av Ximens öden för att undvika att underordna ett medialt uttryck ett annat, eller att Mo Yans litterära strategier förmedlas som en kinesisk representation av en västerländsk litteraturtradition.

\section{Referenser}

\section{Primärlitteratur}

Yan, Mo. Ximen Nao och hans sju liv i översättning från kinesiska av Gustafsson Chen, Anna. Bokförlaget Tranan, 2016.

\section{Sekundärlitteratur}

Abbott, H. Porter (2008), "Narration." I The Cambridge introduction to narrative. 2:ed. Abbot. H, Porter (eds). UK: Cambridge University Press. s. 67-82.

Berry, Michael (2008), A history of pain: Trauma in modern Chinese literature and film. New York: Columbia University Press.

Bruhn, Jørgen (2016), The intermediality of narrative literature: Medialities matter. London: Palgrave Macmillan.

Bruhn, Jørgen (2008), 'Intermedialitet. Framtidens humanistiska grunddisciplin?”, Tidskrift för Litteraturvetenskap. 2008:1. s. 22-37.

Chan W. Shelley (2011), "There is no end to violence", i A Subversive voice in China: The fictional world of Mo Yan. New York: Cambria Press. s. 115-178.

Chengzhou, He (2014), "Rural Chinesness, Mo Yan's work, and world literature", i Mo Yan in context: Nobel Laureate and global storyteller. Duran, Angelica, Huang, Yuhan (eds). West Lafayette, Indiana: Purdue University Press. s. 77-90. (access 2018-03-06).

Chen, Maiping. "The intertextual reading of Chinese literature: With Mo Yan's works as examples", Chinese Today. 5:1. s. 34-36. (access 2018-11-20)

Chi-ying (2014), "Mo Yan's The garlic ballads and Life and death are wearing me out in the context of religious and Chinese literary conventions", i Mo Yan in context: Nobel Laureate and global storyteller. Duran, Angelica, Huang Yuhan (eds). West Lafayette, Indiana: Purdue University Press. s. 123-136. (access 2018-03-06).

De Groot, Jerome (2015), "Pleasure, affect, and performance", I Remaking history, The past in contemporary historical fictions. UK: Routledge. s. 205-218.

Elleström, Lars (2010), Media borders, multimodality and intermediality. Elleström, Lars (red). London: Palgrave Macmillan.

Elliot, Kamilla (2013), "Theorizing adaptations/adapting theories", i Adaptation studies. New challenges, new directions. Bruhn, Jørgen, Gjelsvik, Anne, Frisvold, Hansen. (eds). London: Bloomsbury. s. 19-45. 
Féral, Josette. (2011), [i översättning av Wickes, Leslie], "From event to extreme reality. The aesthetic of shock", Project Muse. MIT Press. TDR: The Drama Review, volume 55. No 4. New York University and the Massachusetts Institute of Technology. s. 51-63. (access 2014-11-11).

Gjelsvik, Anne (2013), "What novels can tell that movies can't show”, i Adaptation studies. New challenges, new directions. Bruhn, Jørgen, Gjelsvik, Anne, Frisvold, Hansen. (eds). London: Bloomsbury. s. 245-264.

Iser, Wolfgang (1993), "Läsprocessen - en fenomenologisk betraktelse", i Modern litteraturteori från rysk formalism till dekonstruktion. Del 1. Entzenberg Claes, Hansson Cecilia (red). Lund: Studentlitteratur. s. 319- 341.

Ohlsson, Anders (1998), Läst genom kameralinsen: Studier i filmiserad svensk roman. Falun: Nya Doxa.

Olsson Anders (2011), "Intertextualitet, komparation och reception", i Litteraturvetenskap en inledning. 2:a uppl. Bergsten, Staffan (red). Lund: Studentlitteratur. s. 51-69.

Paulson, Sarah J (2007), "The body expressed in word and image: an attempt at defining Cora Sandel's aesthetics", i Arvidson, Jens, Askander, Mikael, Bruhn, Jørgen, Führer, Heidrun, (eds), Changing borders: Contemporary positions in intermediality. Lund: Intermedia Studies Press. s. 377-394.

Rippl, Gabriele (2015), "Postcolonial ekphrasis in the contemporary Anglophone Indian novel", i Rippl (eds), Handbook of intermediality: Literature - image - sound - music. Boston: De Gruyter. s. 128-154.

Rossholm, Anna-Sofia (2013), "Auto-adaptation and the movement of writing across media: Ingmar Bergman's notebooks", i Adaptation studies. New challenges, new directions. Bruhn, Jørgen, Gjelsvik, Anne, Frisvold, Hansen. (eds). London: Bloomsbury. s. 203222.

Schirrmacher, Beate (2013), "Trummor och kontrapunkt. Musikens roll i Günter Grass prosa." I DiVA, http://urn.kb.se/resolve?urn=urn:nbn:se:lnu:diva-38899

Sobchack, Vivian (2004), "What my fingers knew: The cinesthetic subject, or vision in the flesh", i Carnal thoughts. Embodiment and moving image culture. London: University of California. https://monoskop.org/images/5/58/Sobchack_Vivian_Carol_Carnal_Thou ghts_Embodiment and Moving_Image_Culture.pdf

Stenström, Kristina (2015), "Monsterkroppar Transformation, transmedialitet och makeoverkultur." I $D$ i $V A$, urn:nbn:se:su:diva-121562

Yuhan, Huang (2014), "Mo Yan's Life and death are wearing me out in a cultural and visual context", I Mo Yan in context: Nobel Laureate and global storyteller. Duran, Angelica, Huang Yuhan (eds). West Lafayette, Indiana: Purdue University Press. s. 123-136. (access 2018-03-06) 